\title{
2014 Mathematics Programs That Make a Difference
}

Each year, the AMS Committee on the Profession (CoProf) selects outstanding programs to be designated as Mathematics Programs That Make a Difference. For 2014 CoProf selected two programs: the CARleton College Summer MATHEMATics PROGRAM (SMP) and Rice UNIVERSITY SUMMER INSTITUTE OF STATISTICS (RUSIS) ${ }^{1}$.

\section{Citation: Carleton College SMP}

Be it resolved that the American Mathematical Society and its Committee on the Profession recognize the Carleton College Summer Mathematics Program (SMP) for its significant efforts to encourage women to continue in the study of mathematics.

Since 1995 the Carleton College Summer Mathematics Program for undergraduate women has been working to increase the probability that the participants will attempt and achieve advanced degrees in mathematics. To date, fifty-six SMP alumnae have earned Ph.D.'s and seventy-one are currently enrolled in graduate programs in the mathematical sciences. The summer program consists of four weeks of intense coursework, seminars, and group discussions all aimed to challenge the participants and provide them with a network of peers and mentors. The program has expanded to include many activities for its extensive network of alumnae. Each summer there is a three-day reunion conference and several recent Ph.D.'s are invited back for two to three weeks to work intensively on their own research programs while serving as mentors to that summer's participants. Through all of their activities, the organizers of SMP have been able to form an impressive vertically integrated network of support and mentoring for and by the members of the SMP community. Alumnae of the program remark on the profound and lasting impact their participation in SMP has had on their careers. They are active, engaged mathematicians who also recognize the importance of mentoring other women in the field.

The AMS commends the Summer Mathematics Program for its high level of commitment and

\footnotetext{
${ }^{1}$ This program has now moved to the University of Nevada at Reno and has been renamed Research for Undergraduates Summer Institute of Statistics at the University of Nevada at Reno, RUSIS@UNR.
}

DOI: http://dx.doi.org/10.1090/noti1129 successful efforts to improve diversity in the profession of mathematics in the United States.

\section{About Carleton College SMP}

"Even today, I regularly feel the effects of the four weeks I spent in Northfield, Minnesota, seventeen years ago," Suzanne Boyd, Associate Professor of Mathematical Sciences, University of WisconsinMilwaukee, commented in her letter of support nominating the Carleton Summer Mathematics Program for Women (SMP) for the AMS Programs That Make a Difference award. In 1995, during the summer between her sophomore and junior years of college, Boyd was a participant in the first year of the Carleton program. "During those four weeks," Boyd summarized, "I found my research area (dynamical systems) and became connected to a network of peers-women in mathematics. That network has continued to grow." That "network" now includes more than 300 other women who have benefited from similar experiences at SMP.

Nearly twenty years ago, Carleton Professors Deanna Haunsperger and Stephen Kennedy launched SMP as a summer opportunity to advance undergraduate women with an interest in mathematics. In 2013 SMP celebrated its seventeenth anniversary. In the intervening years, SMP has welcomed 308 "official" undergraduate participants along with dozens of other women serving as instructors, TAs, speakers, and other guests. Of the 308 summer participants, sixty-two now hold Ph.D.'s (while many are still currently enrolled as undergraduate and graduate students). Based on past trends, Haunsperger and Kennedy project that, out of the eighteen students who take part each summer, eight will go on to finish a Ph.D. in mathematics. That is a striking statistic in light of national trends (see, for example, "Women in science, technology, engineering and math (STEM): A fact sheet" by Kristine De Welde, Sandra Laursen, and Heather Thiry, Sociologists for Women in Society, 2007.)

How do they do it? SMP invites women who have completed one or two years of undergraduate work to the Carleton College campus each summer for four weeks of classes and activities. The SMP students love math, but when they first arrive at the program, most have no understanding of what it means to be a mathematician, let alone what it would take to become one. During the program, 
the directors, faculty, teaching assistants, and mathematicians in residence provide detailed information about exactly what the students need to do over the next few years in order to prepare for graduate school and succeed in completing a Ph.D. in mathematics.

The students take two intense courses to prepare them for the rigors of graduate study. These classes are designed to (i) introduce a student to an area of mathematics that she would probably not find at her home institution, (ii) provide an intensely challenging experience, and (iii) offer a meaningful opportunity for collaborative learning. Women faculty with strong research programs and distinguished teaching records offer these courses that motivate students to learn advanced mathematics. Over the years, SMP class topics have included Morse theory, coding theory, game theory, fuzzy logic, low-dimensional dynamics, knots, and topology.

Beyond the classroom instruction, SMP students engage in a variety of social activities (ranging from home-cooked dinners to an excursion to the Mall of America in nearby Minneapolis), attend biweekly colloquia on a variety of topics in mathematics, and hear panels on practical topics for navigating a career in mathematics. Mary Ellen Rudin gave an SMP colloquium, for example. (Imagine that? An eighteen-year-old learning about topology for the first time in her life from Mary Ellen Rudin!) Joe Gallian, who has run an REU program at the University of Minnesota-Duluth since 1977, is the lone male speaker on the program and often offers his insights on REUs. SMP makes a point to include colloquia on applied mathematics and the history of mathematics. Panel topics include "Making the most of your mathematics major," "Applying, surviving and succeeding at graduate school," and "Nonacademic careers in mathematics." Consequently, SMP provides students with an idea of how to take their immediate next step with finesse and with a vision for what is possible in the long run for a career in mathematics.

The four weeks at Carleton are just the beginning of a rich experience in mathematics for these young women. SMP is structured to bring together alums of the program at different stages of their education and development as mathematicians. Alums who are now in graduate school serve as teaching assistants in the program, while those with Ph.D.'s participate in SMP as speakers and panelists at the annual summer reunion conference (cleverly known as the SMPosium) or as Mathematicians in Residence (MiRs). These former SMP students serve as mentors and role models for the current students. They help current students imagine themselves several years down the road to becoming mathematicians. In this way, the program has maximum impact on its current students, while simultaneously continuing to mentor, advise, and offer opportunities to its former students. By living, working, and playing closely together, students create bonds with each other, with SMP alums, the SMP instructors, and the SMP directors. These relationships continue to foster a supportive community that former SMP participants can rely on throughout their careers. More recently, SMP added a day-long Graduate Education Mentoring workshop (GEM) during the Joint Mathematics Meetings each year for alumnae currently enrolled in Ph.D. programs. Several senior women members of the SMP community (past instructors or visitors, some of the older Ph.D. alums) organize discussions and listen to and provide constructive critiques of talks by graduate student participants.

Karen Lange, assistant professor of mathematics at Wellesley College, views the Carleton SMP as "one of the few constant sources of support throughout my mathematical career, from my undergraduate days to the present." She attended SMP in 1999, the summer after her freshman year of college. "At that point," as Lange put it, "I was far from committed to a career in mathematics. I loved the course work and thrived in the enthusiastic and supportive atmosphere; I left certain I wanted to continue studying mathematics. The program opened my eyes to other resources and opportunities, which I then took advantage of throughout my college years. I cannot emphasize enough how important the SMP network, which is continually growing and being strengthened, has been to my career. After completing a Ph.D. at the University of Chicago and an NSF postdoctoral fellowship at the University of Notre Dame, I am now in a tenuretrack position at Wellesley College. At conferences I regularly run into many SMP alumnae. When I am in need of any kind of advice, whether related to a job search, work-life balance, building a research program, or teaching, I have the network to turn to, and similarly, the network makes me available to support and encourage others. SMP has an incredible impact on those who have been lucky enough to be a part of it."

- Della Dumbaugh, University of Richmond

\section{Citation: RUSIS}

Be it resolved that the American Mathematical Society and its Committee on the Profession recognize the Rice University Summer Institute of Statistics (RUSIS) for its significant efforts to encourage underrepresented minorities and women to continue in the study of mathematics.

The mission of the Rice University Summer Institute of Statistics is to train and mentor underrepresented minority undergraduate students, in particular those students without easy access to career experiences at their own institutions. The fundamental aim of the program is to encourage more students to pursue graduate degrees in 
mathematical and statistical sciences and to facilitate their transition into research. Since RUSIS began in 2001, 83 percent of the participants who have graduated from college have gone on to pursue graduate degrees. This is particularly remarkable because, upon entrance into the program, very few students report considering graduate school as an option for their future. As the alumnae of the program report, RUSIS has a tremendous impact on their professional lives by providing them with a challenging research experience coupled with intensive conversations about their professional and academic futures. Additionally, it is making a profound impact on the numbers of underrepresented minorities in the mathematical sciences. Over the eleven years of the program, 61 percent of the participants have been underrepresented minorities and 53 percent have been female. Three minority participants have received Ph.D.'s and another twenty-five are currently enrolled in Ph.D. programs; many others have completed Master's degrees. As the first REU in statistics, RUSIS has served as a model program for others to emulate, both by encouraging undergraduates to pursue graduate studies in the mathematical sciences and for increasing the numbers of underrepresented minorities and women in mathematics and, in particular, statistics.

The AMS commends the Rice University Summer Institute of Statistics for its high level of commitment and successful efforts to improve diversity in the profession of mathematics in the United States.

\section{About RUSIS}

Today, the need for professionals with high-level quantitative training is increasing in all areas, from medicine to engineering to communications. For work in such areas, a doctorate in statistics opens doors to a broad variety of excellent professional opportunities; yet, many students with an aptitude for studying statistics are unaware of the great opportunities the field offers.

The Rice University Summer Institute of Statistics (RUSIS) stimulates students' interest in statistics by exposing them to actual research problems in the field and by providing guidance and encouragement to pursue a Ph.D. in the mathematical sciences. Established in 2003 by Javier Rojo at Rice University, the program has now moved to the University of Nevada at Reno, where Rojo has taken a position as chair of the mathematics and statistics department. The program has been renamed Research for Undergraduates Summer Institute of Statistics at the University of Nevada at Reno, RUSIS@UNR.

Rojo spent seventeen years at the University of Texas at El Paso, where he founded a math club for undergraduates and worked hard to recruit students from underrepresented groups. In 2001, he moved to Rice University, and two years later he launched RUSIS, with funding from the National Science Foundation and the National Security Agency. As the country's first Research Experiences for Undergraduates program focusing on the field of statistics, RUSIS has been phenomenally successful: Among the RUSIS participants who have now graduated from college, 83 percent have gone on to graduate school. This high percentage is especially remarkable because questionnaires filled out by students at the start of the program indicate that, before participating in RUSIS, only a few had considered graduate school.

Initially, RUSIS had seventeen to nineteen participants each year, and for the past three years it has had twelve students. The program runs for ten intense weeks over the summer. To be admitted to RUSIS, students must typically have done well in a set of prerequisite courses in mathematics. But the program also keeps the door open to accepting students who do not quite meet the academic requirements but who exhibit the kind of perseverance and creativity that signal potential for success in graduate school.

Because the students typically come to RUSIS with varied backgrounds, the mornings of the first three weeks of the program are devoted to an intensive course in probability, stochastic processes, statistical inference, and survival analysis. In the afternoon, students are given a course in computation, which takes place in a computer lab. Here the students gain a working knowledge of computer software needed for their later work in the program. Throughout this period, students are closely supervised and mentored by faculty, who provide intellectual challenges and encouragement, as well as practical information about how to apply to and succeed in graduate school.

During the last six weeks of the program, students form groups and participate in at least one research project in which they analyze data, run computer simulations, develop algorithms, and, when appropriate, engage in theoretical work. With help from postdoctoral associates and graduate students, RUSIS mentors work closely with the students to provide background material specific to the projects, as well as research direction necessary as the projects evolve.

Most of the projects focus on understanding, developing, and assessing the merit of new methodologies in the areas of multivariate survival analysis, multivariate extreme value theory, analysis of microarray data, analysis of massive data sets, and other biomedical and statistical problems. These areas present a wealth of interesting questions, many of which are accessible to undergraduates. Problems of current interest are used to motivate the students and serve as a point of departure for the research projects. Students are expected to prepare presentations about their work, for delivery in the final week of RUSIS and sometimes in 
national meetings. When the work is of sufficient merit, students have written research papers for submission to professional journals.

Throughout the program, RUSIS draws on centers of research and engineering in the Houston area-such as the MD Anderson Cancer Center, the Michael E. DeBakey Department of Surgery at the Baylor College of Medicine, and the University of Texas Health Sciences Center at Houston-to put students in contact with individuals who are doing exciting work. Researchers from these centers come to RUSIS to discuss with the students such topics as survival analysis applications in cancer research, liver transplants, and other healthrelated and environmental applications. Students pay a visit to the Anderson Cancer Center, and they also spend a day touring NASA's Johnson Space Center, where they can operate the flight simulators and visit Mission Control.

In the tenth week, the six-person RUSIS advisory committee, consisting of mathematical scientists from a variety of colleges and universities, visits the program. Students present their work to the committee and interact with the committee members. In addition, the committee members deliver short lectures highlighting how statistics plays a role in their disciplines and providing new perspectives on science and engineering and on career opportunities. Students often comment that these lectures are inspirational. In addition, the students meet with the advisory committee, without RUSIS personnel in attendance, to provide feedback on ways to improve the program.

While open to all students, RUSIS places special emphasis on recruiting students from groups traditionally underrepresented in mathematics and statistics. In this regard, RUSIS has been very successful: Of the 177 RUSIS participants to date, 61 percent are from underrepresented minorities, and 53 percent are female. Of the minority RUSIS alumni, three have obtained Ph.D. degrees and ten have obtained M.S. degrees. Twenty-five minority RUSIS alumni are currently in Ph.D. programs, and many of these are within one or two years of completing their doctorates.

RUSIS has also had a positive impact on the statistics department at Rice University. Before 2001, when RUSIS started, only one student from an underrepresented group had received a Ph.D. in the department. Since 2001, the department has awarded the Ph.D. to eleven individuals who are from underrepresented groups. The success, energy, and excitement engendered by RUSIS has created a change in the departmental culture.

Of course, the real success of RUSIS lies in the way it has transformed the individual lives of the participants. Several RUSIS alumni wrote letters in support of the nomination of RUSIS to receive the Mathematics Programs That Make a Difference award. One of them is Raymundo
Navarrette, a RUSIS alumnus who is now a graduate student at the University of Michigan. Navarrette is a U.S. citizen who grew up with working class parents in Mexico. Within his family background, his obtaining a bachelor's degree at the University of Arizona was already a huge accomplishment. Graduate school had not occurred to him until he attended RUSIS. "Through brilliant and very sincere talks given by the RUSIS director Dr. Javier Rojo and other invited speakers, I was convinced that a doctorate degree would benefit me intellectually and economically and would allow me to do more for my community," Navarrette wrote. "Additionally, the RUSIS program never failed to increase my appetite for more advanced knowledge and to inspire me to dream big."

$$
\begin{array}{r}
\text { - Allyn Jackson, } \\
\text { Notices Deputy Editor }
\end{array}
$$

\section{About the Award}

CoProf created the Mathematics Programs That Make a Difference designation in 2005 as a way to bring recognition to outstanding programs that successfully address the issue of underrepresented groups in mathematics. Each year CoProf identifies one or two exemplary programs that:

1. aim to bring more individuals from underrepresented minority backgrounds into some portion of the pipeline beginning at the undergraduate level and leading to advanced degrees in mathematics and professional success, or retain them in the pipeline;

2. have achieved documentable success in doing so; and

3. are replicable models.

Previously designated Mathematics Programs That Make a Difference are: the graduate program at the University of Iowa and the Summer Institute in Mathematics for Undergraduates/Research Experience for Undergraduates at Universidad de Puerto Rico, Humacao (2006); Enhancing Diversity in Graduate Education (EDGE) and the Mathematical Theoretical Biology Institute (2007); the Mathematics Summer Program in Research and Learning (Math SPIRAL) at the University of Maryland and the Summer Undergraduate Mathematical Science Research Institute at Miami University (Ohio) (2008); the Department of Statistics at North Carolina State University and the Department of Mathematics at the University of Mississippi (2009); the Department of Computational and Applied Mathematics at Rice University and the Summer Program in Quantitative Sciences, Harvard School of Public Health (2010); the Center for Women in Mathematics at Smith College and the Department of Mathematics at North Carolina State University (2011); the Mathematical Sciences Research Institute (2012); and the Nebraska Conference for Undergraduate Women in Mathematics (2013). 